13

\title{
Особенности конденсации кремния на поверхности монокристалла вольфрама
}

\author{
() О.Л. Голубев
}

Физико-технический институт им. А.Ф. Иоффе РАН, Санкт-Петербург, Россия

E-mail: O.Golubev@mail.ioffe.ru

Поступило в Редакцию 31 мая 2018 г.

С помощью методов полевой эмиссионной микроскопии изучалась конденсация $\mathrm{Si}$ на поверхности $\mathrm{W}$ при различных температурах подложки $T$ и количествах $\mathrm{n}$ моноатомных слоев осажденного конденсата. При низких $T \sim 600 \mathrm{~K}$ на поверхности формируется низкотемпературный монослой $\mathrm{Si}$ со структурой чистого $\mathrm{W}$, тогда как при $T \geqslant 1000 \mathrm{~K}$ формируется другая структура высокотемпературного монослоя - поверхностный силицид. Низкотемпературный монослой и поверхностный силицид различаются также и ориентирующим действием при наращивании слоев Si. В случае конденсации на низкотемпературный монослой собственные кристаллиты $\mathrm{Si}$ формируются уже начиная с третьего монослоя $n \geqslant 3$, тогда как при конденсации на поверхностный силицид рост кристаллитов $\mathrm{Si}$ происходит начиная с $n \geqslant 300$ монослоев.

DOI: 10.21883/PJTF.2018.23.47003.17416

Адсорбциия кремния на поверхности вольфрама и происходящие при этом структурные формоизменения являются важными аспектами современной физики поверхности и эмиссионной электроники со многих точек зрения. Подобного рода исследованиям было посвящено достаточно много работ [1,2] в том числе с использованием полевых эмиссионных методов [3-5], которые дают определенные преимущества за счет своей специфики. Однако эти работы касались в основном адсорбции и миграции одиночных атомов $\mathrm{Si}$ и определения энергий активации для миграции на отдельных гранях различных металлов либо изучения начальных стадий образования объемных силицидов различных металлов. 
При этом неизученными оставались вопросы кристаллического роста пленок самого Si на поверхности металлов при широкой вариации количества $\mathrm{n}$ моноатомных слоев (монослоев) сконденсированного адсорбата, а также при значительном изменении температуры подложки $T$. Подобного рода исследования могут, во-первых, позволить выявить интересные закономерности кристаллического роста, а во-вторых - прояснить проблемы создания на поверхности металлов точечных источников электронов и ионов, состоящих как из самого кремния, так и из силицидов металлов. Таким образом, целью настоящей работы является изучение структурных формоизменений слоев Si на W при широких вариациях количества сконденсированного материала и температуры подложки.

Основные эксперименты, результаты которых представлены в работе, были выполнены с помощью методов полевой эмиссионной микроскопии на W. Ряд экспериментов был проведен на Ir и Re, которые дали схожие результаты. Монокристаллические острия с радиусом кривизны в доли микрометров получались методом обычного электролитического травления. Источником Si служила накаливаемая током кремниевая пластина, чистота потока атомов $\mathrm{Si}$ контролировалась с помощью массспектрометра по методике, описанной в [2]. Эксперименты проводились на универсальной установке, позволявшей совмещать режимы работы полевого электронного, ионного и десорбционного микроскопов [6]. Напряженность электрического поля $F$ и работа выхода $\varphi$ определялись традиционными методами по наклону эмиссионных характеристик Фаулера-Нордгейма [7].

Эксперименты показали, что при домонослойных и монослойных покрытиях слой адсорбата может быть в трех принципиально разных структурных состояниях. При $T \leqslant 300 \mathrm{~K}$ на поверхности формируется неупорядоченный практически аморфный слой $\mathrm{Si}$. При $T=450-650 \mathrm{~K}$ происходит упорядочение слоя и образуется структура, которую можно назвать низкотемпературным монослоем, - псевдоморфная структура, примерно соответствующая структуре поверхности чистого W. Наконец, при высоких $T \geqslant 1000 \mathrm{~K}$ (начинается этот процесс уже при $700 \mathrm{~K}$ ) образуется высокотемпературный монослой, при этом происходит реконструкция поверхности: значительно расширяются грани $\{112\}$ и образуются новые грани типа $\{012\}$ вокруг граней $\{001\}$, отсутствующие на поверхности чистого $\mathrm{W}$ и низкотемпературного монослоя. Структуру высокотемпературного монослоя можно назвать поверхностным

Письма в ЖТФ, 2018, том 44, вып. 23 

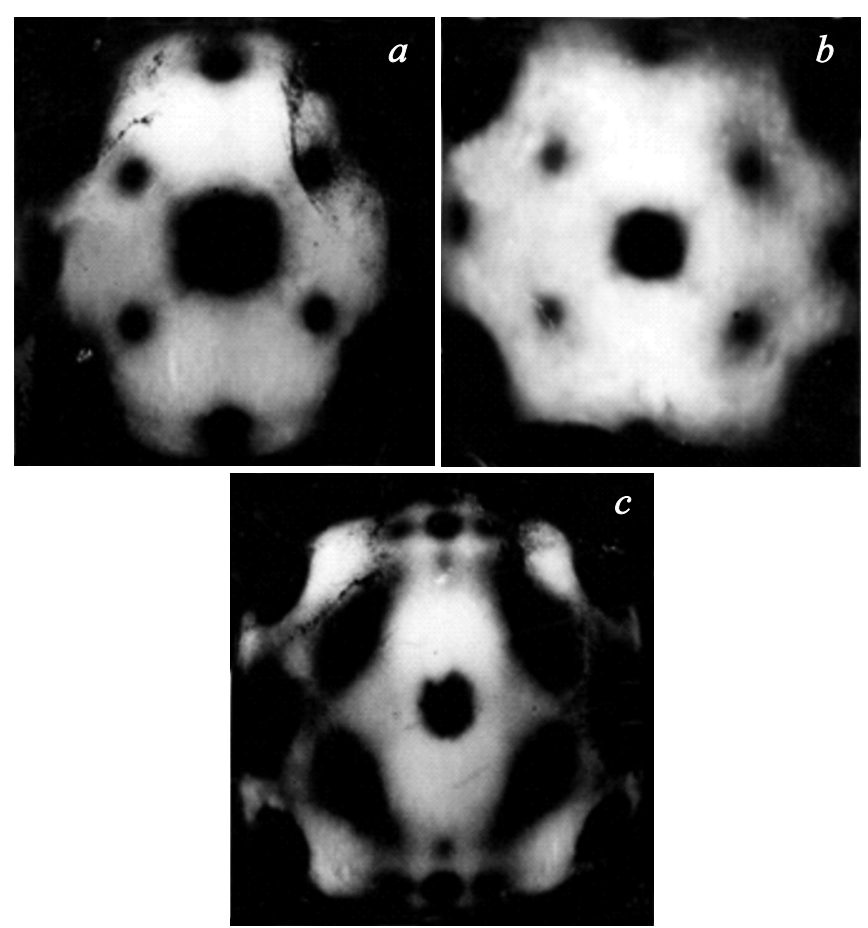

Рис. 1. Полевые электронные изображения поверхности W-эмиттера. Поверхность чистого W $(a)$, поверхность после конденсации одного монослоя $\mathrm{Si}$ при $T=650(b)$ и $1200 \mathrm{~K}(c)$.

силицидом. Данный термин был введен довольно давно авторами [2], при этом под поверхностным силицидом понималось состояние геометрического монослоя $\mathrm{Si}$ на поверхности $\mathrm{W}$, которое возникало при концентрации $n=1 \cdot 10^{15}$ atom $/ \mathrm{cm}^{2}$ атомов $\mathrm{Si}$ на грани $\{100\} \mathrm{W}$, когда на один атом $\mathrm{Si}$ приходится один атом W. Нам представляется, что термином „поверхностный силицид“ лучше характеризовать не любой упорядоченный монослой, а монослойное покрытие, связанное с реконструкцией поверхности подложки, что обусловлено в свою очередь химическим взаимодействием атомов адсорбата и поверхности. Полевые электронные изображения поверхности для низкотемпературного

Письма в ЖТФ, 2018, том 44, вып. 23 

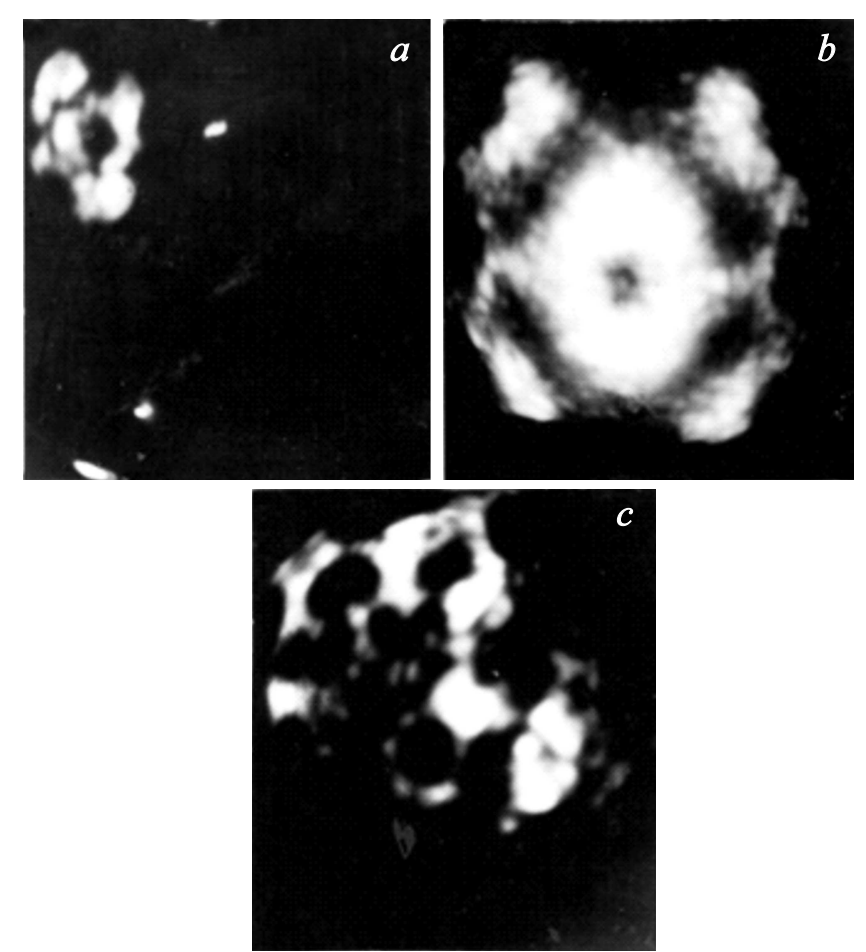

Рис. 2. Полевые электронные изображения поверхности W-эмиттера после конденсации $n=5$ монослоев $\mathrm{Si}$ при $T=650 \mathrm{~K}(a)$, после конденсации одного монослоя $\mathrm{Si}$ при $T=1200 \mathrm{~K}$ и последующей конденсации $n=250$ монослоев $\mathrm{Si}$ при $T=650 \mathrm{~K}(b)$, после конденсации одного монослоя $\mathrm{Si}$ при $T=1200 \mathrm{~K}$ и последующей конденсации $n=300$ монослоев $\mathrm{Si}$ при $T=650 \mathrm{~K}(c)$.

монослоя $\mathrm{Si}$, полученного при $T=650 \mathrm{~K}$, и поверхностного силицида, полученного при $T=1200 \mathrm{~K}$, показаны на рис. $1, b$ и $c$ соответственно (на рис. 1, $а$ представлены данные для чистого W).

Главным различием между низкотемпературным монослоем и поверхностным силицидом является разное ориентирующее действие при наращивании на них новых слоев. Если конденсацию $\mathrm{Si}$ проводить на поверхность низкотемпературного монослоя, то уже начиная с небольших покрытий $n \geqslant 3$ можно наблюдать образование мелких

Письма в ЖТФ, 2018, том 44, вып. 23 
кристаллитов Si. На рис. 2, а показано образование подобных кристаллитов при $n=5$ и $T=650 \mathrm{~K}$. Если же конденсацию проводить на поверхность, соответствующую поверхностному силициду, то характер ростового процесса совершенно иной. Рис. 2, $b$ демонстрирует полевое электронное изображение поверхности, соответствующее эксперименту, который проводился следующим образом. Сначала при температуре $T$ острия $1200 \mathrm{~K}$ конденсировался монослой $\mathrm{Si}$ и получался поверхностный силицид, показанный на рис. 1,c, затем температура острия опускалась до $T=650 \mathrm{~K}$ и проводилась конденсация следующих слоев Si. Видно, что даже при конденсации 250 монослоев наблюдается поверхностная структура, характерная для поверхностного силицида, и собственные кристаллиты $\mathrm{Si}$ не образуются (рис. 2,b). Только при достижении покрытий $n \sim 300$ монослоев (рис. 2,c) наблюдается образование значительного количества кристаллитов $\mathrm{Si}$ с собственной огранкой. Таким образом, эксперименты, некоторые стадии которых показаны на рис. 2, позволяют сделать вывод, что при конденсации $\mathrm{Si}$ на поверхность низкотемпературного монослоя реализуется механизм роста Странского-Крастанова, когда один, а может быть, и два монослоя экранируют влияние подложки, после чего становится возможным рост собственных кристаллитов Si. В случае же конденсации на поверхностный силицид реконструкция создает поверхность, благоприятную для наращивания почти невозмущенных (ненапряженных) слоев $\mathrm{Si}$ с единой цельной структурой поверхностного силицида. Однако в конце концов неполная изоморфность и накапливание структурных несоответствий приводят к формированию собственных кристаллитов Si. Следовательно, в данном случае реализуется механизм роста Франка-Ван дер Мерве. Хотя W и $\mathrm{Si}$ неизоморфны, реконструкция поверхности $\mathrm{W}$ делает возможным формирование на ней значительного количества (более 200) псевдоморфных слоев как переходной стадии от чистого W к чистому Si. Низкотемпературный монослой и поверхностный силицид различаются также и по электронным свойствам. В случаях осаждения как при $T=650 \mathrm{~K}$, так и при $T=1200 \mathrm{~K}$ адсорбция Si вызывает плавное повышение средней работы выхода вольфрама $\varphi$, при этом наблюдается максимум при $n=1$. Однако в случае низкотемпературного монослоя $\varphi_{\max }=4.95 \mathrm{eV}$, затем $\varphi$ плавно падает до величины $\varphi=4.85 \mathrm{eV}$, соответствующей среднему значению $\varphi$ для $\mathrm{Si}$ при покрытии $n \geqslant 2$, тогда как в случае поверхностного силицида величина $\varphi_{\max }=4.95 \mathrm{eV}$ далее не меняется с ростом покрытия, так как весь сверхмонослойный

Письма в ЖТФ, 2018, том 44, вып. 23 
кремний диффундирует в объем $\mathrm{W}$ вплоть до формирования объемного силицида $\mathrm{WSi}_{2}$. Подобную картину наблюдали и авторы работы [2].

При $T \geqslant 900 \mathrm{~K}$ уже наблюдается заметная диффузия атомов $\mathrm{Si}$ в объем W. Объемная диффузия имеет место лишь при сверхмонослойных покрытиях, как это отмечалось и в работе [2], и процесс объемной диффузии приводит к образованию объемного силицида $\mathrm{WSi}_{2}$. Образование силицида происходит наиболее интенсивно в областях граней куба $\{100\}$, где параметры ОЦК-решетки $\mathrm{W} a=0.316 \mathrm{~nm}$ и тетрагональной плотноупакованной решетки $\mathrm{WSi}_{2} c=0.322 \mathrm{~nm}$ наиболее близки. В этом случае, так же как и в случае адсорбции углерода на W, сначала формируется структура так называемого „ребристого кристалла“ $[8]$, который можно охарактеризовать как первую стадию силицидообразования $\mathrm{W}$, поскольку ОЦК-решетка $\mathrm{W}$ не может скачком перестроиться в ГПУ-решетку $\mathrm{WSi}_{2}$. При этом если долго выдерживать структуру $\mathrm{WSi}_{2}$ при $T=1300 \mathrm{~K}$, то объемный силицид растворится и на поверхности будет наблюдаться картина поверхностного силицида, который всегда предшествует образованию $\mathrm{WSi}_{2}$ при напылении $\mathrm{Si}$, a также получению чистого $\mathrm{W}$ при прогреве объемного силицида. Полевое испарение поверхности показывает наличие узких ребер моноатомной ширины в областях центральной грани $\{110\}$ и в областях $\{100\}$. С помощью графиков Аррениуса для скорости диффузии $\lg v=f(1 / T)$ были определены энергия активации объемной диффузии $\mathrm{Si}$. Подобный график дал величину энергии $Q=2.85 \pm 0.05 \mathrm{eV}$ и предэкспоненциальный множитель $\tau_{0}=3 \cdot 10^{-10} \mathrm{~s}$. Близкую по значению величину $Q$ получили и авторы работы [2], однако в предположении изначально принятого „теоретического“ значения величины предэкспоненциального множителя $\tau_{0} \sim 10^{-13} \mathrm{~s}$.

При одновременном воздействии сильных электрических полей и высоких температур на слои $\mathrm{Si}$ на $\mathrm{W}$ в случае поверхностного силицида происходит реконструкция поверхности $\mathrm{W}$ [9], и на центральной грани $\{110\} \mathrm{W}$ появляются одиночные наноразмерные наросты, которые могут служить эффективными точечными источниками электронов, поскольку обладают весьма высокой локальной яркостью. Состав этих наростов представляет собой смесь силицидов $\mathrm{WSi}_{2}$ и $\mathrm{WSi}$ [10].

Таким образом, главный вывод работы состоит в том, что на одной и той же исходной поверхности $\mathrm{W}$ при одной и той же ее температуре и в случае конденсации одного и того же адсорбата $(\mathrm{Si})$ могут реализоваться разные механизмы роста, приводящие к совершенно 
различным конечным результатам в зависимости от того, в каком состоянии находится исходная поверхность покрытой монослоем адсорбата подложки. Собственные кристаллиты $\mathrm{Si}$ на W можно получить при конденсации Si как начиная с 3 монослоев, так и начиная примерно с 300 монослоев в зависимости от состояния поверхности W, покрытой $\mathrm{Si}$.

\section{Список литературы}

[1] Flaim T.A., Ownby P.D. // Surf. Sci. 1972. V. 32. N 3. P. 519-526.

[2] Gall N.R., Rutkov E.V., Tontegode A.Ya. // Thin Solid Films. 1995. V. 266. P. 229-238.

[3] Tsong T.T., Wang S.C., Liu H.F. // J. Vac. Sci. Technol. B. 1983. V. 1. P. 915-922.

[4] Tsong T.T. // Surf. Sci. Rep. 1988. V. 8. N 3/4. P. 127-207.

[5] Nishikava O., Tomori M., Iwawaki F. // Surf. Sci. 1992. V. 266. P. 204-213.

[6] Голубев О.Л. // ЖТФ. 2011. Т. 81. В. 6. С. 113-119.

[7] Fowler R.H., Nordheim L. // Proc. Roy. Soc. A. 1928. V. 119. N 781. P. 173-181.

[8] Голубев О.Л. // Письма в ЖТФ. 2009. Т. 35. В. 12. С. 18-24.

[9] Голубев О.Л., Конторович Е.Л., Шредник В.Н. // ЖТФ. 1996. Т. 66. В. 3. C. $88-96$.

[10] Логинов М.В., Шредник В.Н. // Письма в ЖТФ. 2003. Т. 29. В. 13. С. 1-9.

Письма в ЖТФ, 2018, том 44, вып. 23 